\title{
QUALITY INDICATORS IN RADIATION ONCOLOGY: Proposal of the SPANISH SOCIETY OF RADIATION ONCOLOGY (SEOR) for a continuous improvement of the quality of care in oncology.
}

\author{
Authors and filiations
}

J. López Torrecilla ${ }^{a}$, S. Marín I Borràs ${ }^{b}$, A. Ruiz-Alonso ${ }^{c}$, J. Jaen Olasolo ${ }^{\text {d }}$, M.L. Vazquez de la Torre $^{\mathrm{e}}$, E. Bóveda Carrof, A. Rodriguez Pérez ${ }^{\mathrm{g}}$, E. Ignacio García ${ }^{\mathrm{h}}$, F. Caballero Martínez ; F.J. Campos Lucas $^{\mathrm{j}}$; P.C. Lara Jiménez ${ }^{\mathrm{k}}$, J. Contreras Martínez ${ }^{1}$, C. Ferrer Albiach ${ }^{\mathrm{m}}$

a. Department of Radiation Oncology-ERESA. Hospital General Universitario de Valencia. Av. Tres Cruces, 2. 46007-Valencia (Spain)

b. Department of Radiation Oncology. Hospital Duran i Reynals, Institut Català d'Oncologia. Avinguda de la Granvia, 199; 08908, L'Hospitalet de Llobregat, Barcelona. smarin@iconcologia.net

c. Department of Radiation Oncology. Hospital Universitario Doce de Octubre (Madrid). Avda. de Córdoba s/n, 28041 Madrid, Spain. aruialo@gmail.com

d. Department of Radiation Oncology. Hospital Universitario Puerta del Mar. Instituto de Investigación Biomédica de Cádiz (INiBICA). Av Ana de Viya, 21, 11009 Cádiz, Spain. Jjaen2008@gmail.com

e. Department of Radiation Oncology. Hospital Do Meixoeiro. Camiño Meixoeiro, s/n, 36214 Vigo (Pontevedra) Spain. maria.luisa.vazquez.de.la.torre.gonzalez@sergas.es

f. Department of Radiation Oncology. Hospital Universitario Cruces. Plaza de Cruces, S/N, 48903 Baracaldo, Vizcaya. Spain. ELSIRA.BOVEDACARRO@ osakidetza.net

g. Department of Radiation Oncology, Hospital Ruber Internacional, Calle de la Masó, 38, 28034 Madrid, Spain. arodriguez@ ruberinternacional.es

h. Departamento de Enfermería y Fisioterapia. Universidad de Cádiz. Avda. Ana de Viya, 52, 11009, Cádiz, Spain. emilio.ignacio@uca.es

i. School of Health Sciences. Francisco de Vitoria University, Ctra. Pozuelo-Majadahonda (M-515) Km. 1.800, 28223, Pozuelo de Alarcón, Madrid, Spain. Email: $\underline{\text { f.caballero@ufv.es }}$

j. School of Health Sciences. Francisco de Vitoria University, Ctra. Pozuelo-Majadahonda (M-515) Km. 1.800, 28223, Pozuelo de Alarcón, Madrid, Spain. Email: f.campos@ufv.es

k. Department of Radiation Oncology, Hospital Universitario Dr Negrín, Barranco de la Ballena s/n. 35010 Las Palmas de Gran Canaria, Spain. Clinical Oncology, Universidad de Las Palmas, Las Palmas, Spain. plara@dcc.ulpgc.es

1. Vice-president SEOR. Department of Radiation Oncology. Hospital Regional Universitario Carlos Haya. Av. de Carlos Haya, s/n, 29010 Málaga. jorgecontrerasmartinez@ gmail.com

m. President SEOR. Department of Radiation Oncology, Consorcio Hospitalario Provincial de Castellón, Avda del Dr Clará 19, 12002 Castellón, Spain. ferreralbiach@ @mail.com

\section{Corresponding author}

- Name José López Torrecilla

- Filliation Servicio Oncología Radioterápica-ERESA. Hospital General Valencia (Spain)

- Email: jltorrecilla@eresa.com

- Phone 34.961972173

- Movil-phone: 34670356338 


\section{Acknowledgements}

We thank all the participants in the Delphy study for helping to contribute to improve the situation of RO in Spain; the participant's names and affiliations are listed in Appendix 1.

\section{Compliance with Ethical Standards:}

Declaration of conflict of interest:

The Quality Indicators in Radiation Oncology is a scientific initiative by the Spanish Society of Radiation Oncology (SEOR).

The authors declare that they have no conflict of interest. 


\begin{abstract}
Purpose: Current cancer treatment options include surgical intervention, radiotherapy and chemotherapy. The quality of the provision of each of them and their effective coordination determines the results in terms of benefit/risk. Regarding the radiation oncology treatments, there are not stabilised quality indicators to be used to perform control and continuous improvement processes for healthcare services. Therefore, the Spanish Society of Radiation Oncology has undertaken a comprehensive project to establish quality indicators for use with the information systems available in most Spanish healthcare services. Methods: A two-round Delphi study, examining consensus of several possible quality indicators $(n=28)$ in daily practice. These indicators were defined after a bibliographic search and the assessment by radiation oncology specialists $(n=8)$. They included aspects regarding treatment equipment, patient preparation, treatment and follow-up processes and were divided in structure, process and outcome indicators. Results: After the evaluation of the defined quality indicators $(n=28)$ by an expert panel (38 radiation oncologist); 26 indicators achieved consensus in terms of agreement with the statement. Two quality indicators did not achieve consensus. Conclusions: There is a high degree of consensus in Spanish Radiation Oncology specialists on which indicators in routine clinical practice can best measure quality. These indicators can be used to classify services based on several parameters (patients, equipments, complexity of the techniques used and scientific research). Furthermore, these indicators allow assess our current situation and set improvements objectives.
\end{abstract}

Keywords: Radiation Oncology; Quality indicators; Delphi; Consensus; Healthcare Services. 


\section{PURPOSE}

The Institute of Medicine [1] reported (2001) 1\% of deaths every year caused by medical errors in Unites States (US). Many reasons could promote this situation; the most frequent are: treatment delays, dose errors, treatment delivery errors, unsuitable treatments or errors in treatment equipment.

The three synergistic pillars of the current cancer treatment are surgery, radiotherapy and chemotherapy. The quality of the provision of each of them and their effective coordination determine to outcomes.

Radiation oncology (RO) quality assurance in Spain is regulated by law [2]; however, this law does not establish the definition of any type of quality indicators to be used to perform control and continuous improvement processes for healthcare services. This study focuses on: RO treatments, the instrumental quality control (including treatment equipment and patient preparation), treatment and follow-up processes.

In cancer patients, the National Cancer Institute [3] defines quality of care as "the provision of evidence-based, patientcentered services throughout the continuum of care in a timely and technically competent manner, with good communication, shared decision making, and cultural sensitivity, with the aim of improving clinical outcomes, including patient survival and health-related quality of life (QoL)".

The complexity of the quality of cancer care is impossible to measure without suitably comprehensive indicators to assess the various components of quality and which are sensitive to progressive and regressive changes in daily practice.

The Spanish Society of RO (SEOR), concerned with ensuring the best possible care to each patient, has undertaken a comprehensive project for the continuous quality improvement in Spanish RO. The aim of this project is to select, prioritize and define some indicators of use suitability and quality of healthcare for SEOR. The first part of this project was realized by an expert Working Group (WG) that selected the quality indicators that SEOR proposes as appropriate for use with the information systems available in most Spanish healthcare services. On this basis, the project will continue to promote quality measurements in these services and to establish individual/collective improvement objectives. The study was completed establishing detailed standards of good practice for each indicator selected (and additional information to facilitate their correct use and widespread implementation) in collaboration with Spanish Society for Healthcare Quality (SECA, for their initials in Spanish). 


\section{METHODS}

Collaborative project for professional consensus promoted by SEOR, involving RO specialists assisted by SECA specialists and a university technical-team specialized in qualitative research techniques and group dynamics. The process was carried out in 4 consecutive phases, each with different aims and participants, between February and December 2015.

Phase 1: Literature review of the study subject matter by a search in biomedical databases (Medline, Excerpta Médica, CancerLIT, National Guideline Clearinghouse, Cochrane Library Plus, Guía Salud, Lilacs, IME). The objective was to identify previous proposals, at national or international level, regarding criteria, indicators and healthcare quality standards in RO; either in general or linked to specific pathologies.

The extensive collection of publications founded $(n=38)$, with information on appropriate use and healthcare quality in RO (original articles, systematic reviews, expert consensus, clinical guidelines, healthcare technology evaluation reports, and other technical documents), was analyzed and evaluated by an WG. This WG was composed of eight RO specialists, with interest and/or training in healthcare quality. They analyzed the quality of the documents, identifying possible quality indicators and choosing and transcribing those considered appropriate for Spanish RO for discussion among professionals in the subsequent phases of the project.

Subsequently, based on the expert input (who suggested between 10 and 28 items) to avoid concept repetition or overlap; the specialized members of the technical team produced a common documentary base of 48 possible clearlydefined indicators (Table 1). According to the classification proposed by Donabedian [4], this initial set was composed of 7 structure indicators, 24 process indicators and 17 outcome indicators (including the treated patients opinion).

Phase 2. Pre-selection of indicators subject to professional consensus. The WG set the international aim of not exceeding 25 indicators, completely covering the patient preparation, the treatment and the follow-up process in RO services. The aim was to ensure the manageability of the final proposal indicators in the improvement plans of the specific healthcare units and the viability of measuring them under real standard practice

Each group member assessed the relevance of each of the 48 indicators proposed (secret vote), using a scale of 0-10 (lowest-highest relevance), considering the 0-4 range score as a "non-critical indicator", and the 5-10 range as an "essential indicator". The group was then informed of the average score for each indicator after their initial positioning. 
After free discussion, a second round of secret vote was performed to confirm the final selection of the items with the greatest support. In this round, each member could accept a maximum of 20 indicators; the rest would be rejected. Eventually, 28 indicators with the most support were chosen ( 8 structure, 15 process and 5 outcome indicators) (Table $1)$.

Phase 3. Validation of the final selection of the indicators chosen by structured professional consensus. A tworounds Delphi technique was carried out to involve an external representative of the WG in the final approval process of the definitive indicators that SEOR would like to disseminate as its own.

A Panel of Experts was constituted with 38 of the 51 expert radiation oncologists invited, using a snowball or chain sampling strategy among SEOR associates. All members, with broad geographical representativeness (nationwide), had recognised professional prestige in the field of study,

Given the experts' expected systematic support for all items (practically all of which are from prestigious scientific documentary sources), the objective was: to endorse the suitability of each indicator and to determine the priority among the indicators according to the need to be implemented in the evaluation processes regarding healthcare quality in the specialty.

The Delphi method is a distance professional consensus technique using written surveys broadly used in biomedical research. This technique allows to explore and bring together the opinions of a professional group on the topic of interest without the difficulties and inconveniences inherent to face-to-face consensus meetings [5].

The method requests the individual/anonymous opinion of each panellist through a confidential online survey. The survey is repeated in a second round, after disseminating the group results of the first questionnaire and the written comments made by the panellists among the participants. This provides an opportunity for each participant to reflect and reconsider his/her opinion between the rounds, without the change in opinion being obvious to the rest of the panellists. The technique preserves anonymity, allows for controlled interaction between the group (without the risk of influence biases due to the presence of dominant members) and, finally, it objectively validates the consensus level achieved by statistical criteria.

Each item was assessed using a single nine-point Likert ordinal scale, with three ordinal regions set by linguistic qualifiers: 
- 1-3: "I disagree with" (lower score implies lower degree of agreement).

- 4-6: "I do not agree or disagree with; I do not have a fully defined opinion on the issue" (choose 4 or 6 if you are closer to disagreeing or agreeing, respectively).

- 7-9: "I agree with" (higher score implies higher degree of agreement).

After each round, the group's opinion and the consensus reached on each issue raised was determined by the position of the group's median score and the "level of agreement" reached by the respondents, according to the following criteria:

- Consensus is considered to be reached regarding an item when there is "agreement" of panel opinion on the panel: that is, when less than one third of the respondent experts score outside the three-point region (1-3), (4-6), (7-9) which contains the median. In this case, the median value determines the group consensus reached: "majority" disagreement" with the item, if the median is $\leq 3$, or majority "agreement" with the item if the median is $\geq 7$. The cases in which the median falls within the 4-6 region will be considered "uncertain" items.

- Conversely, it is established that exists panel opinion differences in the panel opinion when the scores of one third or more of the panellists are in the (1-3) region and another third or more are in the (7-9) region. The remaining items without agreement or disagreement is observed will be considered to have an "undetermined".

All items without a clear consensus (uncertain items, those with disagreement and those "undetermined") are proposed for reconsideration in the second round. Items with a high dispersion of opinion (interquartile range $\geq 4$ points; range of scores contained between the p25 and p75 values of the distribution), are also re-evaluated.

Between the rounds, the panellists were informed of response distribution in the first survey (bar charts) and comments and clarifications provided by each participant. After reviewing this information, they were asked to give a new opinion on the items not agreed in the first round.

In addition, the second round also entailed a prioritisation scale aimed at assigning an order of priority among the various indicators in each block (structure, process and outcome). 
Phase 4. Express formulation of a standardised version of the indicators selected according to SECA's conventional technical format (Table 1). Setting out for each indicator: quality criterion, indicator statement, definition and clarifications of terms, formula for calculating the indicator, indicator type (structure, process, outcome), justification, calculation period, compliance level (standard/acceptable), information source for measurement, and bibliography.

The university technical group and SECA experts developed a proposal for each item, which was submitted for approval to the SEOR WG. The definition of standards for each indicator (the appropriate compliance benchmarks) was based on available information from the literature consulted. Where such information was not available, the WG determined the values by consensus.

\section{RESULTS}

In the first Delphi round regarding the 28 possible indicators evaluated (from the process described in the section of methods), the usefulness of 23 indicators was established by consensus. No indicators were rejected. In the second round, the 5 indicators not previously agreed upon were revaluated and three reached agreement. Two indicators were eliminated due to insufficient agreement (not due to unanimous rejection by the group). Therefore, the expert panel validated 26 of the 28 indicators analyzed (93\% of the initial proposal) (Figure 1).

Table 1 contains the 28 indicators with their detailed results at the end of both rounds. The tables 2 and 3 show the indicators with their justification and the formula to follow-up, respectively.

\section{DISCUSSION}

With this project, we have established the indicators that could best measure the decision, preparation and treatment process in RO. For this purpose we have followed the framework used in the "Patterns of Care" in RO, developed between the years 1994-1997 by Hanks [6], for prostate, breast and cervical cancer in the US to evaluate the quality of treatments among different populations. One of the objectives of this "Patterns of Care" was the model of Donabedian (1988), which classified quality indicators in clinical practice [4] into three categories: structure, processes and outcomes. 
Structure indicators analyze the set-up characteristics where patient care is provided, which includes material, human and organisational resources. Therefore, in this section we chose as indicators the number of patients treated per radiation oncologist and per treatment unit, distinguishing between the treatment complexity and type used (external beam radiotherapy; brachytherapy), common in most quality indicator studies. This is primarily based on surgical data that showed better results in hospitals with larger volumes of patients [7]. The treatment equipment quality and their obsolescence may have an impact on its operation; therefore we also introduced the quantification of interruptions due to breakdowns and patient referrals that may be due to equipment shortages. From the point of view of the organization, we believe that joint decision-making regarding treatments in tumour committees guarantees a better therapeutic choice and, therefore, knowing the percentage of patients evaluated in them must be taken into account. Finally, RO departments are not available in all hospitals, which sometimes make the access difficult, delay the treatment initiation and determine their end result. Thus, it was important to assess the accessibility of the service.

Most of these structure indicators have been considered by different authors and societies and are considered for accreditation programmes. The advantage of these indicators is that they are usually easy to gather, given that there are recommendations on their values ranges. This is a controversial point, because the available ranges are very wide and so it is vitally important to know the real values of Spanish RO departments, which can better set the quality of these indicators. As Hayman says [8], although structural characteristics are important to provide good care, they do not guarantee quality per se, and so the relationship between structural performance and quality is more implied than proven.

Process indicators measure what is actually done, the activities realized by professionals to decide upon, prepare and administer a treatment, thus showing the internal working of the organisation to manage their work in a consistent manner. Process indicators are often based on clinical trial data and are primarily focused on what we do and how we do it, and allow us to take swift action for improvement. Given the influence that processes have on the final service quality and that they are often considered the best quality measures [9], this is where we observed the most impact, having defined 15, with which we believe we are covering most of the RO department facets. Using them, our aim is to assess their capacity to respond to treatment demands with indicators such as the department response time and the time required for the treatment preparation process. We also pretend to assess the knowledge and equipment in order to apply it, using indicators such as the appropriate dose of external beam radiotherapy or brachytherapy in prostate 
cancer, patients with head and neck tumours treated with intensity modulation, patients receiving fractionated extracranial stereotactic radiotherapy, the percentage of verifications performed throughout the treatment, patients with rectal cancer receiving neoadjuvant radiotherapy or retreated patients and re-irradiated patients. The treatment duration is a factor that affects the equipment workloads and the QoL of patients and their loved ones and, therefore, we believe the use of hypofractionated treatment regimens in prostate and breast cancer should be evaluated. Finally, malfunctions in established work processes can also lead to increased workloads and so we wanted to measure patients who require rescheduling, not due to tumour changes during treatment, and also those patients who receive treatment for longer than planned.

Outcome indicators measure the effect of the care received by patients on their health and their satisfaction level. Thus, we place considerable value on the complications rate and patient satisfaction. In addition, we have included three other indicators that may indirectly influence the results: the medical records quality, reflecting the essential data to decide upon a treatment; the publications of the department, due to their impact on the analysis of the patients being treated; and the number of patients in prospective clinical studies due to what is set out in the regulations required by trials.

We are aware that outcome indicators are usually focused on analysing the final effect of the treatment (survival, disease control); however, at least in the first phase, we have not considered them because of difficulty in collecting them, the time required to be significant, in case of survival 5-10 years, and the complexity due to the final outcomes in most tumours depend on multiple factors external to the RO departments, such as diagnosis delays, unsuitable surgery, improper instructions prior to radiotherapy, etc. Nevertheless, we have considered others which may lead to improvement measures in our preparation and treatment processes.

The care burden of RO services often makes it difficult to collect data for the indicators we have defined, but fortunately our services now have more and more electronic systems that were initially designed exclusively to reduce the risk of errors and control the operation of linear accelerators. These systems were later extended to connect the scheduling and treatment systems and eventually expanded to electronic systems that store demographic, staging, prescription and treatment data. 
With the support of these information systems, we must collect data prospectively to have quality indicators in a fast and simple way. Most data used to obtain the indicators can be easily extracted from the information systems available to most RO departments, even if in some cases it is necessary to make some modifications.

In summary, we completely agree with Hayman statement [8] "I believe assessment of the quality of the care we deliver is central to improving the care that we provide to our patients and is an area in which we as radiation oncologists should assume a leadership role”.

The Delphi method seemed to us to be the most appropriate due to providing a better intersubjective/prospective understanding of the difficult subject that is quality indicators in RO. In addition, it allows us to analyze preferences among the participants and to discuss the need for each of the indicators, as they are ultimately the ones who are going to use them. Finally, it allows us to create a current of opinion regarding the need to measure the quality of daily clinical practice and RO departments.

Study limitations. Some of the reference quality indicator comes from data of authors environment, due to the lack of published data; therefore this data may not be corroborated by other Spanish departments and is, consequently, exposed to future modifications throughout the different phases of this project.

Conclusions. This is the first SEOR project to measure the quality of RO departments using objective quality indicators. These indicators are a starting point for assessing our current situation and setting collective and individual improvement objectives. There is significant consensus among participants regarding which indicators can best measure quality in RO. These indicators can be used to classify services not only by the number of patients and equipment they have installed, but also by the complexity of the techniques they use, their participation in research projects and the scientific activity they carry out. 


\section{REFERENCES}

1. Committee On Quality of Health Care in America IoM. Crossing the Quality Chasm: A New Health System for the 21st Century. 2001.

2. RD 1566/1998 of 17 july, which sets quality standards in radiotherapy. 1998.

3. Institute NC. National Cancer Institute: The Nation's Investment in Cancer Research: A Plan and Badget Proposal for Fiscal Year 2004. Bethesda: NIH Publication No. 03-4373; 2002.

4. Donabedian A. The quality of care. How can it be assessed? JAMA. 1988(260):1743-8.

5. Dalkey N, Brown B, Cochran S. The Delphi Method, III: Use of Self Ratings to Improve Group Estimates. Santa Monica (California): Rand Corporation; 1969.

6. Hanks GE CL, Curry J. Patterns of Care studies: Past, present and future. Semin Radiation Oncology. 1997;7:97-100.

7. Ellison LM HJ, Birkmeyer JD. The effect of hospital volume on mortality and resource use after radical prostatectomy. J Urol. 2000;163:867-9.

8. Hayman J. Measuring the Quality of Care in Radiation Oncology. Seminars in Radiation Oncology. 2008;18:201-6.

9. Brook RH ME, Shekelle PG. Defining and measuring quality of care: A perspective from US researchers. Int J Qual Helth Care. 2000;12:281-95.

10. Bentzen SM, Heeren G, Cottier B, et al. Towards evidence-based guidelines for radiotherapy infrastructure and staffing needs in Europe: the ESTRO QUARTS project. Radiotherapy and Oncology. 2005;75:355365 .

11. Rosenblatt E, Izewska J, Anacak Y, et al. Radiotherapy capacity in European countries: ananalysis of the Directory of Radiotherapy Centres (DIRAC) database. Lancet Oncol. 2013;14:e79-86.

12. Lievens Y, Dunscombe P, Defourny N, et al. HERO (Health Economics in Radiation Oncology): a panEuropean project on radiotherapy resources and needs. Clin Oncol (R Coll Radiol). 2015;27:115124./opencms/es/noticias/Indicadores-de-calidad-y-seguridad-para-la-atencin-a-pacientes-con-tratamientoanticoagulante-oral/

13. Dusscombe P, Grau C, Defourny et al Guidelines for equipment and staffing of radiotherapy facilities in European countries: Final results of the ESTRO-HERO survey. Radiotherapy and Oncology 2014 Aug;112(2):165-77

14. Lievens Y, Defourny N, Coffey M. et al. Radiotherapy staffing in the European countries: Final results from the ESTRO-HERO survey. Radio ther Oncol (2014) Aug;112(2):178-86.

15. Slotman Ben J, Cottier B.,Bentzen SM et al Overview of National Guidelines for infrastructure and staffing of Radiotherapy. ESTRO-QUARTS. Radiother Oncol 75(2005) 349e1-349 e6

16. Ministerio de Sanidad y Política Social. Estrategia en Cáncer del Sistema Nacional de Salud. Madrid; 2010.

17. Saura RM, Gimeno V, Blanco MC, Colomer R, Serrano P, Acea B, et al. Desarrollo de indicadores de proceso y resultado y evaluación de la práctica asistencial oncológica. Informe de evaluación de tecnologías sanitarias (AATRM 2006/02). Madrid: Ministerio de Sanidad y Consumo; 2007.

18. Cooper T, Williams MV. Implementation of intensity-modulated radiotherapy: lessons learned and implications for the future. Clin Oncol (R Coll Radiol) 2012;24:539-42.

19. De NW, De GW, Madani I. Rational use of intensity-modulated radiation therapy: the importance of clinical out come. Semin Radiat Oncol 2012;22:40-9.

20. Mayles WP on be half of the Radiotherapy Development Board. Survey of the availability and use of advanced radiotherapy technology in the UK. Clin Oncol (R Coll Radiol ) 2010;22:636-42. 
21. Staffurth J. A review of the clinical evidence for intensity-modulated radiotherapy. Clin Oncol (R Coll Radiol ) 2010;22:643-57.

22. Herruzo I, Romero J, Palacios A et al. Libro Blanco SEOR XXI. Madrid: Editores Médicos, 2010.

23. Observatoire National de la Radiothérapie. Situation fin 2013 et évolution depuis 2009. BoulogneBillancourt: Institut National du Cancer, 2015

24. Castelli J, Simon A, Louvel G, Henry O, Chajon E, Nassef M et al: Impact of head and neck cancer adaptative radiotherapy tos pare the parotidglands and decrease the risk of xerostomia. Radiat Oncol 2015; 10(1): 6.

25. Yang H, Hu W, Wang W, Chen P, Ding W, LuoWl:

Replanningduringintensitymodulatedradiationtherapyimprovedquality of life in patients with naso pharyngeal carcinoma. Int J Radiat Oncol Biol Phys 2013; 85(1): e47-54.

26. Jadon R, Pembroke CA, Hanna CL, Palaniappan N, Evans M, Cleves AE, Staffuth J: A systematic review of organ motion and image-guided strategies in external beam radiotherapy for cervical cancer. Clin Oncol 2014; 26(4): 185-96

27. Radiotherapy risk profile WHO/IER/PSP/2008.12

28. F. Soldá, M. Lodge,S. Ashley, el al. Stereo tactic radiotherapy (SABR) for the treatment of primary nonsmall-celllung cáncer; Systematic review and comparis on with a surgicalcohort. Radiotherapy and Oncology 109(2013):1-7

29. A. Saghal, D. Roberge, D. Schellenberg el al. The Canadian Association Oncology Scope of Practice Guidelines for Lung, Liver and spine Stero tactic Body Radiotherapy. ClinicalOncology 24 (2012):629639.

30. IASLC Muldisciplinary Approach to Thoracic Oncology 2014.

31. ESMO guidelines.

32. A. Gasinska, J.F. Fowler, BK Lind. Influence of Overall Treatment Time and Radiobiological Parameters on Biologically Effective Doses in Cervical Cancer Patients Treated with Radiation Therapy Alone. Acta Oncológica Vol. 43, No. 7, pp. 657-666, 2004

33. JA Gonzalez Ferreira, J Jaen Olasolo, I Azinovic, B. Jeremic. Effect of radiotherapy delay in overall treatment time on local control and survival in head and neck cancer: Review of the literatura. Rep Pract Oncol Radiother 20(5): 328-339. 2015

34. E.Ben-Josef, J. Moughan, J.A. Ajani, M.Flam, L. Gunderson, et al. Impact of Overall Treatment Time on Survival and Local Control in Patients With Anal Cancer: A Pooled Data Analysis of Radiation Therapy Oncology Group Trials 87-04 and 98-11. JCO 28: 5061-5066. 2010.

35. NCCN Clinical Practice guidelines in Oncology Prostate Cancer. Version 2.2017. www.nccn.org/patients

36. Guidelines on Prostate Cancer. European Association of Urology 2016. https://uroweb.org/

37. MJ Zelefsky, WR Lee, A Zietman, N Khalid, Ch Crozier, J Owen, JF Wilson. Evaluation of adherence to quality measures for prostate cancer radiotherapy in the United States: Results from the Quality Research in Radiation Oncology (QRRO) Survey. POR 2013; 3: 2-8.

38. Michalski H, Gay H, Jackson A, et al. Radiation dose-volume effects in radiation-induced rectal injury. Int J Radiat Oncol Biol Phys. 2010;76(suppl):S123-S129.

39. Stone NN, Stock RG, Cesaretti JA, Unger P. Local control following permanent prostate brachytherapy: effect of high biologically effective dose on biopsy results and oncologic out comes. Int J Radiat Oncol BiolPhys. 2010 Feb 1;76 (2):355-60.

40. Crook JM, Potter L, Stock RG, Zelefsky MJ. Critical organdosi metry in permanent seed prostate brachy therapy: Defining the organs at risk. Brachytherapy. 2005;4:186-194. 
41. C.N. Catton, H. Lukka, Chu-Shu Gu, J.M. Martin, et al. Randomized Trial of a Hypofractionated Radiation Regimen for the Treatment of Localized Prostate Cancer. JCO 35: March 15. 2017

42. Dearnaley D, Syndikus I, Mossop H, et al: Conventional versus hypofractionated high-dose intensitymodulated radiotherapy for prostate cancer: 5-year outcomes of the randomised, noninferiority, phase 3 CHHiP trial. Lancet Oncol 17: 1047-1060, 2016.

43. Pollack A, Walker G, Horwitz EM, et al: Randomized trial of hypofractionated external-beam radiotherapy for prostate cancer. J Clin Oncol 31:3860-3868, 2013.

44. Aluwini S, Pos F, Schimmel E, et al: Hypofractionated versus conventionally fractionated radiotherapy for patients with prostate cáncer (HYPRO): Late toxicity results from a randomised, non-inferiority, phase 3 trial. Lancet Oncol 17: 464-474, 2016.

45. Gomez-Millan J, Jerez I, Perez A, et al. Potential advantages of volumetric arc therapy in head and neck cancer.Head Neck. 2015 Jun;37(6):909-14.

46. Zhang B, Mo Z, Du W, et al. Intensity-modulated radiation therapy versus 2D-RT or 3D-CRT for the treatment of nasopharyngeal carcinoma: A systematic review and meta-analysis. Oral Oncol. 2015 Nov;51(11):1041-6.

47. Marta GN, Silva V, de Andrade Carvalho H, et al. Intensity-modulated radiation therapy for head and neck cancer: systematic review and meta-analysis. Radiother Oncol. 2014 Jan;110(1):9-15.

48. Arenas M, Sabater S, Gascón M, Henríquez I, Bueno MJ, Rius A: Quality a ssurance in radiotherapy: analysis of the causes of not starting or early radiotherapy with drawal. Radiat Oncol 2014; 9: 260.

49. Bujold A, Craig T, Jaffray D, et al. Image-guided radiotherapy: has itinfluenced patient out comes? Semin Radiat Oncol. 2012;22:50-61.

50. ACR-ASTRO PRACTICE PARAMETER FOR IMAGE-GUIDED RADIATION THERAPY (IGRT). ACR-ASTRO Practice Parameter for Radiation Oncology. https://www.acr.org/

51. POSITION PAPER ON IMAGE GUIDED RADIATION THERAPY (IGRT) 2015. Faculty of Radiation Oncology. The Royal Australian and New Zeland College of Radiologists. www.ranzcr.edu.au.

52. Valle LF, Agarwal S, Bickel KE, et al. Hypofractionated whole breast radiotherapy in breast conservation for early-stage breast cancer: a systematic review and meta-analysis of randomized trials. Breast Cancer Res Treat. 2017 Apr;162(3):409-417.

53. Speers C, Pierce LJ. Postoperative Radiotherapy After Breast-Conserving Surgery for Early-Stage Breast Cancer: A Review. JAMA Oncol. 2016 Aug 1;2(8):1075-82.

54. Sauer R., Liersch T, Merkel S, Fietkauer R, Hohenberger W, Hess C et al: Preoperative vs post operative chemo radiotherapy for locally advanced rectal cancer: results of the German CAO/ARO/AIO-94 randomized phase III trial after a median follow-up of 11 years. J ClinOncol 2012; 30(6): 1926-33.

55. Wesswlman S, Winter A, Ferencz J, Seuffenlein T Post S: Documented quality of care in certified colorectal cancer centres in Germany: German Cancer society benchmarking report for 2013. In J Colorectal Dis 2014; 29: 511-58.

56. Joseph KJ, Al-Mandhari Z, Pervez N, et al. Reirradiation after radical radiation therapy: a survey of patterns of practiceamong Canadian radiation oncologists. Int J Radiat Oncol Biol Phys 2008;72:1523-9.

57. Yamazaki H, Fushiki M, Mizowaki T and the Kansai Cancer Therapist Group. A surveillance study of the current status of reirradiation and patterns of practice. Journal of Radiation Research, 2016, pp. 1-8.

58. McDonald MW, Lawson J, Garg MK, et al. ACR appropriatenesscriteriaretreatment of recurrent head and neckcancerafter prior definitiveradiationexpert panel onradiationoncology-head and neckcancer. Int J RadiatOncolBiolPhys 2011; 80:1292.

59. Chen AM, Phillips TL, Lee NY. Practicalconsiderations in the re-irradiation of recurrent and secondprimary head-and-neckcancer: who, why, how, and howmuch? Int J RadiatOncolBiolPhys 2011; $81: 1211$. 
60. Strojan P, Corry J, Eisbruch A, et al. Recurrent and secondprimarysquamouscell carcinoma of the head and neck: when and how to reirradiate. Head Neck 2015; 37:134.

61. McDonald MW, et al. Reirradiation of recurrent and secondprimary head and neckcancerwithprotontherapy. Int J RadiatOncolBiolPhys 2016; 4:808.

62. Perez and Brady's. Principles and Practice of Radiation Oncology, 6th Edition. 2013. Lippincott Williams \& Wilkins. Chapter 13. Late Effects and QUANTEC.

63. Poinsot R, Altmeyer A, Conroy T, et al. Multisite validation study of questionnaire assessing out-patient satisfaction with care questionnaire in ambulatory chemotherapy or radiotherapy treatment. Bull Cancer 2006; 93(3): 315-327.

64. Arraras JI, Illarramendi JJ, Viudez A, et al. Determinants of patient satisfaction with care in a Spanish oncology day hospital and its relationship with quality of life. Psychooncology. 2013 Nov;22(11):2454-61.

65. Arraras JI, Rico M, Vila M, Chicata V, et al. The EORTC cancer outpatient satisfaction with care questionnaire in ambulatory radiotherapy: EORTC OUT-PATSAT35 RT. Validation study for Spanish patients. Psychooncology. 2010 June;19(6):657-664.

66. W.A.M. van Lent, R.D. de Beer, B. van Triest, et al. Select ing indicators for international benchmarking of radio therapy centers. Journal of Radiotherapy in Practise(2013)12,26-38.

67. Indicadores para el Análisis de la asistencia en Oncología Radioterápica. Plan Director de Oncología Marzo de 2009. Generalitat de Catalunya. Departamento de salut.

68. Van Lent WA, de Beer RD, van Harten WH. International benchmarking of specialty hospitals. A series of case studies on comprehensive cancer centres. BMC Health Serv Res 2010; 10:253.

69. Ley 41/2002, de 14 de noviembre, básica reguladora de la autonomía del paciente y de derechos y obligaciones en materia de información y documentación clínica. 